\title{
RESÍDUO DE CURTUMES COMO FONTE DE NITROGÊNIO PARA TRIGO E ARROZ EM SUCESSÃO
}

\author{
Lívia Cristina Coelho(1), Mozart Martins Ferreira ${ }^{(1)^{*}}$, Ana Rosa Ribeiro Bastos ${ }^{(1)}$, Luiz Carlos
}

Alves de Oliveira $^{(2)}$ e Ewerton Dilelis Ferreira ${ }^{(1)}$

(1) Universidade Federal de Lavras, Departamento de Ciência do Solo, Lavras, Minas Gerais, Brasil.

(2) Universidade Federal de Minas Gerais, Departamento de Química, Belo Horizonte, Minas Gerais, Brasil.

* Autor correspondente.

E-mail: mozartmf@dcs.ufla.br

\section{RESUMO}

O processo de estabilização necessário para o curtimento das peles, na indústria coureira, gera grande quantidade de resíduo sólido colagênico com elevado potencial poluidor. Esse resíduo contém elevado teor de nitrogênio, o que confere ao resíduo potencial para uso agrícola. Para avaliar a viabilidade da aplicação de rejeito da indústria do couro, como fonte nitrogenada para as culturas do trigo e arroz de sequeiro, foi implantado um experimento em casa de vegetação com cinco doses de $\mathrm{N}$ provenientes do colágeno $(0,225$, 450,675 e $900 \mathrm{mg} \mathrm{kg}^{-1}$ ) e três tratamentos adicionais (controle, ureia e ureia reposta no segundo cultivo). A aplicação de até $675 \mathrm{mg} \mathrm{kg}^{-1}$ de $\mathrm{N}$ via colágeno propiciou produção de matéria seca de plantas de trigo similar à aplicação de $\mathrm{N}$ mineral e maior massa de grãos de trigo em todas as doses estudadas (14 a $41 \%$ superiores à aplicação de $\mathrm{N}$ mineral). Como fonte residual, a aplicação do colágeno proporcionou níveis de $\mathrm{N}$ no solo suficientes para obter massa de grãos de arroz nas doses mais elevadas (acima de $675 \mathrm{mg} \mathrm{kg}^{-1}$ de $\mathrm{N}$ via colágeno), sem que os teores de $\mathrm{Cr}$ foliares sejam considerados tóxicos. $\mathrm{O}$ colágeno pode ser boa alternativa para a implantação da cultura do arroz após a colheita de trigo, sem prejuízos de produtividade e necessidade de reposição de fertilizantes nitrogenados, se aplicado na dose $675 \mathrm{mg} \mathrm{kg}^{-1}$ de $\mathrm{N}$ fornecido via colágeno.

Palavras-chave: rejeito, couro wet blue, nitrogênio, Oryza sativa L., Triticum aestivum L.

ABSTRACT: LEATHER INDUSTRY WASTE AS A NITROGEN SOURCE FOR WHEAT AND RICE IN SUCCESSION 
The stabilization process necessary for leather tanning, in the leather industry, generates a great deal of collagenic solid waste, which is a likely pollutant. This solid waste has high nitrogen content, which suggests potential for agricultural use. To evaluate the feasibility of application of industrial leather waste as an $N$ source for wheat and rice crops, a greenhouse experiment was conducted with five application rates of $N$ from collagen $\left(0,225,450,675\right.$, and $\left.900 \mathrm{mg} \mathrm{kg}^{-1}\right)$ and three additional treatments (control, urea, and urea replenished in the second crop). The application of up to $675 \mathrm{mg} \mathrm{kg}^{-1}$ of $\mathrm{N}$ via collagen led to shoot dry matter production of wheat plants similar to application of mineral $N$ fertilization, and increased wheat grain weight at all application rates studied (14 to $41 \%$ higher than the application of mineral $N$ ). Collagen as a residual source provided $N$ levels in the soil sufficient to obtain higher levels of rice grain weight (above $675 \mathrm{mg} \mathrm{kg}^{-1}$ of $\mathrm{N}$ via collagen), without leaf $\mathrm{Cr}$ contents being considered toxic. Collagen could be a good alternative for establishing the rice crop after wheat without yield losses and need for replacement of $N$ fertilizers if applied at a rate corresponding to $675 \mathrm{mg} \mathrm{kg}^{-1}$ of $\mathrm{N}$ supplied through collagen.

Keywords: waste, wet blue leather, nitrogen, Oryza sativa L., Triticum aestivum L.

\section{INTRODUÇÃO}

A indústria coureira está entre os grandes geradores de resíduos potencialmente poluidores. Para que seja comercializado, o couro deve passar por um processo de curtimento, que visa conservá-lo e melhorar suas características físicas e químicas. O processamento de uma tonelada de peles gera $200 \mathrm{~kg}$ de couro como produto final, cerca de $250 \mathrm{~kg}$ de resíduos sólidos de couro não curtido e $200 \mathrm{~kg}$ de resíduos curtidos, assim como 50 mil kg de águas residuárias (Erdem e Ozverdi, 2008; Kolomaznik et al., 2008).

Os curtumes, de 80 a $90 \%$ deles, utilizam para o processo de curtimento sais de cromo trivalente $\left(\mathrm{Cr}^{3+}\right)$, gerando com isso resíduos ricos nesse elemento. Classificado como resíduo Classe I, de acordo com a norma NBR 10.004 (ABNT, 2004), é um dos mais perigosos e nocivos, se descartado no ambiente sem tratamento adicional. Os métodos para sua eliminação incluem aterros ou incineração, que possuem altos custos operacionais. Admite-se que, essencialmente, o $\mathrm{Cr}$ fornecido via colágeno é o $\mathrm{Cr}^{3+}$, e no solo essa forma constitui grande número de complexos, tanto com ligantes orgânicos quanto inorgânicos (Losi et al., 1994). Com elevação do pH do solo, proporcionada pela calagem, a formação de compostos insolúveis como $\mathrm{Cr}(\mathrm{OH})_{3}$ é favorecida, sendo essa considerada a reação predominante do $\mathrm{Cr}^{3+}$ no solo (Cary et al., 1977; James e Bartlett, 1983; Rai et al., 1989; Silva, 1989). O Cr pode também permanecer ligado à matéria orgânica, formando complexos de esfera interna e reduzindo a disponibilidade para as plantas (Mertz, 1969; Becquer et al., 2003).

Processos capazes de tratar os rejeitos dos curtumes, agregando valor e possibilitando sua reutilização, constituem atualmente um tópico de grande importância ambiental e econômica, principalmente nos locais onde o processamento do couro é uma atividade importante. Nesse sentido, Oliveira et al. (2004) desenvolveram e patentearam uma técnica capaz de retirar o $\mathrm{Cr}$ e recuperar um material sólido colagênico com elevado teor de $\mathrm{N}$ intitulada "Processo de reciclagem de resíduos sólidos de curtumes por extração do cromo e recuperação do couro descontaminado" (INPI; Processo patenteado Br. n. PI 001538), a patente visa recuperar o $\mathrm{Cr}$ do rejeito, reutilizando-o no processo de curtimento, bem como o reaproveitamento do colágeno nas indústrias de fertilizantes.

No Brasil, estudos com a aplicação no solo de resíduos de couro curtido ao Cr são recentes (Ribeiro, 2006; Abichequer et al., 2008). O resíduo colagênico de couro wet blue, se apresentou como boa alternativa de fonte nitrogenada para o crescimento de algumas culturas como o capim-elefante (Pennisetum purpureum Schumach. cv. Napier) (Oliveira et al., 2008) e feijão (Phaseolus vulgaris L.) (Lima et al., 2010). Nesses trabalhos, foi observado, entretanto, que o resíduo de couro wet blue (sem extração de $\mathrm{Cr}$ ) não disponibiliza o $\mathrm{N}$ durante os cultivos evidenciando que a extração do $\mathrm{Cr}$ é fundamental para o seu uso como fonte de nutrientes na agricultura. O colágeno foi utilizado incorporado com $\mathrm{P}$ e $\mathrm{K}$ minerais para a produção de formulações Ncolágeno-P-K, obtendo resultados promissores para a cultura de arroz (Nogueira et al., 2010).

Neste trabalho, objetivou-se avaliar a eficiência do resíduo de couro wet blue (colágeno), previamente submetido à extração de $\mathrm{Cr}$, como fonte de $\mathrm{N}$ para as culturas de trigo (efeito imediato) e arroz (efeito residual).

\section{MATERIAL E MÉTODOS}

O experimento foi realizado no Departamento de Ciência do Solo (DCS) da Universidade Federal de Lavras (UFLA). O solo utilizado no experimento foi classificado como Latossolo Vermelho Distrófico típico, textura muito argilosa (Embrapa, 2006). O solo foi analisado conforme Embrapa (1997); e o 
teor de Cr total, de acordo com USEPA (1998) e apresentava as seguintes características químicas: $\mathrm{pH}\left(\mathrm{H}_{2} \mathrm{O}\right)(1: 2,5) 4,8 ; 0,6 \mathrm{mg} \mathrm{dm}^{-3}$ de $\mathrm{P} ; 14 \mathrm{mg} \mathrm{dm}^{-3}$ de $\mathrm{K} ; 1,5 \mathrm{mg} \mathrm{dm}^{-3}$ de $\mathrm{Cu} ; 75,4 \mathrm{mg} \mathrm{dm}^{-3}$ de $\mathrm{Fe}$; $4,9 \mathrm{mg} \mathrm{dm}^{-3}$ de Mn; 0,6 mg dm${ }^{-3}$ de Zn e $1,2 \mathrm{mg} \mathrm{dm}^{-3}$ de Cr, extraídos por Mehlich-1; $6 \mathrm{mmol}_{\mathrm{c}} \mathrm{dm}^{-3} \mathrm{de}$

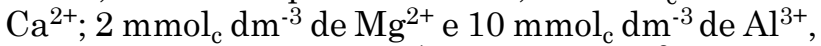
extraídos por $\mathrm{KCl} 1 \mathrm{~mol} \mathrm{~L}^{-1} ; 70 \mathrm{mmol}_{\mathrm{c}} \mathrm{dm}^{-3} \mathrm{de} \mathrm{H}+\mathrm{Al}$, determinado por solução SMP; 10,7 \% de saturação por bases (V); $41 \mathrm{~g} \mathrm{~kg}^{-1}$ de matéria orgânica (MO), método Walkey-Black; $0,3 \mathrm{mg} \mathrm{dm}^{-3}$ de $\mathrm{B}$, extraído

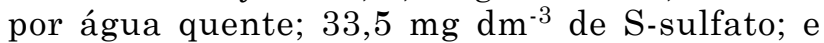
$236,9 \mathrm{mg} \mathrm{dm}^{-3}$ de Cr (USEPA 3051).

Resíduos de couro contendo $\mathrm{Cr}$, na forma de serragem e aparas, foram tratados conforme recomendação de Oliveira et al.(2004), com a geração de um resíduo sólido (colágeno), que foi submetido às análises físico-químicas, conforme método oficial do Ministério da Agricultura, Pecuária e Abastecimento (Brasil, 2007). Esse material apresentou 98,7\% (m/m) de sólidos voláteis; $390 \mathrm{~g} \mathrm{~kg}^{-1}$ de C orgânico; $148 \mathrm{~g} \mathrm{~kg}^{-1}$ de N (Kjeldahl); relação C/N 2,6; $1986 \mathrm{mg} \mathrm{kg}^{-1}$ de Cr total; poder de neutralização $\left(\mathrm{PN} \mathrm{CaCO}_{3}\right)$ 14,4\%; $\mathrm{pH}\left(\mathrm{H}_{2} \mathrm{O}\right) 7,4$; e umidade gravimétrica de $7,57 \%$.

Adotou-se o delineamento inteiramente casualizado, com oito tratamentos (cinco doses de colágeno e três tratamentos adicionais) e três repetições. Cada unidade experimental foi composta de $9 \mathrm{~kg}$ de solo acondicionados em vaso. Os cinco tratamentos referentes às doses de colágeno corresponderam à aplicação de 0, 3, 6, 9 e $12 \mathrm{Mg} \mathrm{ha}^{-1}$, equivalentes a $0,225,450,675$ e $900 \mathrm{mg} \mathrm{kg}^{-1} \mathrm{de} \mathrm{N}$. Essas quantidades do colágeno foram calculadas de acordo com o teor total de $\mathrm{N}$ presente $\left(148 \mathrm{~g} \mathrm{~kg}^{-1}\right)$. Utilizou-se como referência a dose de $450 \mathrm{mg} \mathrm{kg}^{-1} \mathrm{de}$ $\mathrm{N}$, recomendada para adubações em experimentos em casa de vegetação até a produção de grãos (Malavolta, 1980). Constituíram os tratamentos adicionais: Adicional 1 - controle sem adubo e sem colágeno; Adicional 2 - adubação convencional do trigo com $\mathrm{N}$ mineral (ureia), correspondendo à dose de $450 \mathrm{mg} \mathrm{kg}^{-1}$ de $\mathrm{N}$ e sem reposição no cultivo do arroz; e Adicional 3 - adubação convencional do trigo com $\mathrm{N}$ mineral (ureia), na dose de $450 \mathrm{mg} \mathrm{kg}^{-1}$ e reposição de $450 \mathrm{mg} \mathrm{kg}^{-1}$ de $\mathrm{N}$ na forma de ureia no segundo experimento com arroz. No segundo cultivo (arroz), o colágeno não foi reposto, com a finalidade de se avaliar o efeito residual do $\mathrm{N}$ proveniente do colágeno.

Antes da semeadura, aplicaram-se carbonato de cálcio (p.a.) e hidroxicarbonato de magnésio (p.a.) na relação Ca:Mg 3:1, para elevar a saturação por bases a $50 \%$, como recomendado por Ribeiro et al. (1999). O colágeno e a calagem foram aplicados simultaneamente ao solo, e os vasos foram incubados por 15 dias, com umidade mantida em $60 \%$ do volume total de poros (VTP). A seguir, no plantio do trigo, foram adicionados, em mg kg-1 de solo, P: 200, K: 350, Ca: 80, Mg: 30 e S: 50; e B: 0,5; Cu: 1,5; Zn: 5; e Mo: 0,1, na forma de reagentes (p.a.) em solução (Malavolta, 1980). O N na forma de ureia (nos tratamentos adicionais 2 e 3 ) e o $\mathrm{K}$ foram parcelados em quatro aplicações iguais: no plantio e aos 30, 45 e 75 dias após a semeadura. No tratamento-controle (solo natural), não foi realizada nenhuma adubação ou correção de acidez do solo.

Foram colocadas 12 sementes de trigo por vaso, deixando-se quatro plantas por vaso após desbaste. Após 52 dias da emergência das plântulas, no início do florescimento, duas plantas foram cortadas rente ao solo para determinar a matéria seca de parte aérea e as análises foliares, e as duas restantes foram mantidas até o final do ciclo. Ao final do experimento, as plantas restantes foram cortadas e a parte aérea foi separada em folhas + colmos e panículas. Para analisar a translocação do $\mathrm{Cr}$ para os grãos, foi calculado o percentual de Cr nos grãos de trigo em relação a todo $\mathrm{Cr}$ absorvido pela parte aérea. Após a colheita do trigo, foi implantado o experimento com a cultura do arroz de sequeiro. Foram mantidas quatro plantas por vaso até o $1^{\circ}$ corte (57 dias após a emergência das plântulas, no início do florescimento), e as duas plantas restantes foram mantidas até o final do ciclo ( $2^{\circ}$ corte). No estádio de maturação fisiológica, todas as plantas de cada vaso e cultivo tiveram as panículas separadas em grãos e casca dos grãos. A produção relativa foi calculada como percentual da produção proporcionada em relação à aplicação do $\mathrm{N}$ mineral.

O material vegetal colhido foi seco em estufa com circulação forçada de ar à temperatura de $60^{\circ} \mathrm{C}$ até atingir massa constante e pesado para obter a massa da matéria seca. Posteriormente, foi moído em moinho tipo Willey com peneira de 20 mesh para determinar as concentrações de $\mathrm{N}$ e Cr. O N foi determinado por destilação a vapor após digestão sulfúrica (Bataglia et al., 1983), enquanto o $\mathrm{Cr}$ foi determinado por espectrofotômetro de absorção atômica em chama de ar-acetileno (Varian AA-175 series) em extrato digerido em solução nítrico-perclórica (Malavolta et al.,1997).

Os dados obtidos nos cultivos foram submetidos à análise de variância e, quando ocorreram efeitos significativos pelo teste $\mathrm{F}$, foram realizadas análises de contrastes e de regressão, com o programa estatístico SISVAR (Ferreira, 2003). Os modelos para ajuste das equações foram escolhidos com base coeficiente de determinação e na sua significância $(p<0,05)$. Os efeitos da utilização da ureia foram contrastados com os da utilização do colágeno.

\section{RESULTADOS E DISCUSSÃO}

\section{Produção de matéria seca em plantas de trigo}

Os tratamentos influenciaram a produção de matéria seca da parte aérea, tanto no $1^{\circ}$ corte quanto no $2^{\circ}$, bem como a produção de grãos de trigo. As 
plantas evidenciaram resposta quadrática às doses de $\mathrm{N}$ aplicadas, sendo os valores máximos da produção de matéria seca alcançados na dose de $437,5 \mathrm{mg} \mathrm{kg}^{-1}$, no $1^{\mathrm{o}}$ corte; $625 \mathrm{mg} \mathrm{kg}^{-1}$, no $2^{\mathrm{o}}$ corte; e $557,4 \mathrm{mg} \mathrm{kg}^{-1}$, para a produção de grãos (Figura 1). A análise de contrastes revelou que as doses 450 e $675 \mathrm{mg} \mathrm{kg}^{-1} \mathrm{de} \mathrm{N}$ provenientes do colágeno apresentaram efeito igual para produção de matéria seca da parte aérea (tanto no $1^{\circ}$ quanto no $2^{\circ}$ corte, $\mathrm{p}<0,05$ ), quando comparadas à dose de $\mathrm{N}$ mineral (450 $\mathrm{mg} \mathrm{kg}^{-1}$ ) recomendada (Malavolta, 1980).

A dose de $900 \mathrm{mg} \mathrm{kg}^{-1}$ de $\mathrm{N}$ via colágeno acarretou menor produção de matéria seca de parte aérea em a mbos os cortes, quando comparada à adubação com $\mathrm{N}$ mineral. Esse efeito pode ter sido causado pela elevada concentração de $\mathrm{Cr}$ fornecida pelo colágeno e também pelo excesso de $\mathrm{N}$ disponibilizado. Em altas concentrações, o $\mathrm{Cr}$ pode causar estresse oxidativo induzindo a degradação de pigmentos fotossintéticos e consequente diminuição do crescimento (Taiz e Zeiger, 2004). Além disso, enzimas antioxidantes são suscetíveis ao $\mathrm{Cr}$, resultando em declínio das suas atividades catalíticas (Taiz e Zeiger, 2004). Com relação à matéria seca grãos, o fornecimento de $\mathrm{N}$ via colágeno nas doses de 450 e $675 \mathrm{mg} \mathrm{kg}^{-1}$ propiciou produções superiores àquela alcançada com a utilização da ureia.

\section{Acúmulo de $\mathrm{N}$ em plantas de trigo}

$\mathrm{O}$ aumento das doses de $\mathrm{N}$ via colágeno provocou elevação nos teores desse nutriente na parte aérea do trigo (Figura 2). Os teores adequados de $\mathrm{N}$ foliar em trigo estão entre 30 e $33 \mathrm{~g} \mathrm{~kg}^{-1}$ (Malavolta et al., 1997). Quando se aplicou N via colágeno, foram observados, no $1^{\circ}$ corte, os teores de $\mathrm{N}$ de 38,2 ; 41,$9 ; 42,5$; e $50,0 \mathrm{mg} \mathrm{kg}^{-1}$, respectivamente, para as doses $225,450,675$ e $900 \mathrm{mg} \mathrm{kg}^{-1}$ de $\mathrm{N}$, teores esses superiores aos considerados adequados por aqueles autores. Deve-se destacar que o $1^{\circ}$ corte foi realizado no início do florescimento, considerado como época diagnóstica preferencial.

As plantas de trigo no $2^{\circ}$ corte apresentaram teores de $\mathrm{N}$ inferiores aos observados no $1^{\circ}$ corte $\mathrm{e}$ aos descritos como adequados por Malavolta et al. (1997). Nos grãos, foi observado um comportamento quadrático com teor máximo atingido na dose de $597 \mathrm{mg} \mathrm{kg}^{-1}$ (Figura 2).

No $1^{\circ}$ corte, os teores de $\mathrm{N}$ na parte aérea nas plantas que receberam $\mathrm{N}$ proveniente do colágeno foram iguais ou superiores àqueles das plantas fertilizadas com $\mathrm{N}$ mineral (ureia). No entanto, no $2^{\circ}$ corte, nas plantas que receberam $\mathrm{N}$ mineral foram verificados maiores teores de $\mathrm{N}$, exceto para a dose de $900 \mathrm{mg} \mathrm{kg}^{-1}$ de $\mathrm{N}$ via colágeno. Os teores de $\mathrm{N}$ nos grãos não diferiram estatisticamente com relação às fontes de $\mathrm{N}$ colágeno e $\mathrm{N}$ mineral.

$\mathrm{O}$ acúmulo de $\mathrm{N}$ na parte aérea no $1^{\circ}$ corte e nos grãos evidenciou resposta quadrática, com redução da produção de matéria seca das plantas nas maiores
- Colágeno $\Delta \mathrm{N}$ mineral o Solo natural (Controle)

(a)

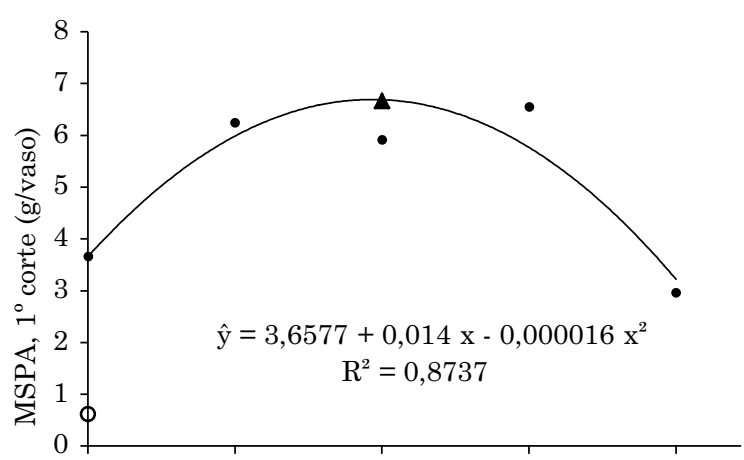

(b)

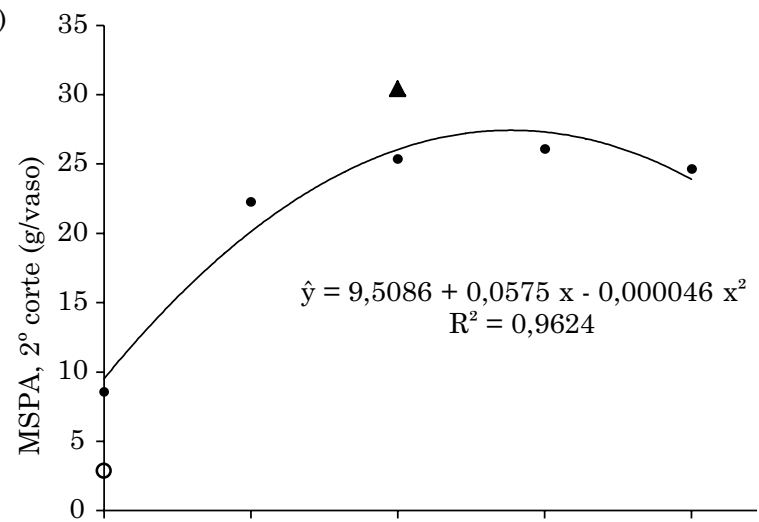

(c)

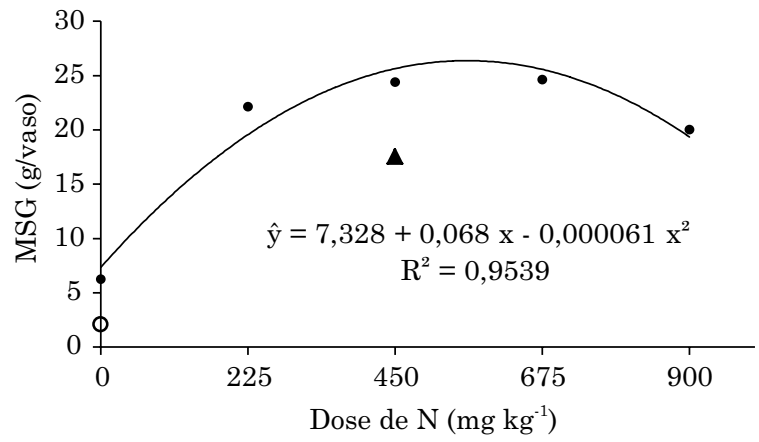

Figura 1. Produção de matéria seca de parte aérea (MSPA) no $1^{\circ}$ corte (a) e no $2^{\circ}$ corte (b) e nos grãos (MSG) (c) em plantas de trigo submetidas a doses de nitrogênio via colágeno de curtume e dois tratamentos adicionais, cultivadas em Latossolo Vermelho Distrófico típico.

doses de N (Figura 2). Isso se deve provavelmente à excessiva quantidade de $\mathrm{N}$ aplicada, que foi acompanhada de elevada concentração de Cr. Para o acúmulo de $\mathrm{N}$ na matéria seca no $2^{\circ}$ corte, foi observada resposta linear positiva com o aumento das doses de N.

As quantidades de $\mathrm{N}$ acumuladas nas aplicações de 225,450 e $675 \mathrm{mg} \mathrm{kg}^{-1}$ de $\mathrm{N}$ via colágeno, no $1^{\circ}$ corte, não diferiram das plantas que receberam ureia. $\mathrm{Na}$ maior dose de $\mathrm{N}$ fornecida via colágeno $\left(900 \mathrm{mg} \mathrm{kg}^{-1}\right)$, o acúmulo foi inferior ao $\mathrm{N}$ mineral. No $2^{\circ}$ corte, os 
(a) Colágeno $\Delta \mathrm{N}$ mineral o Solo natural (Controle)

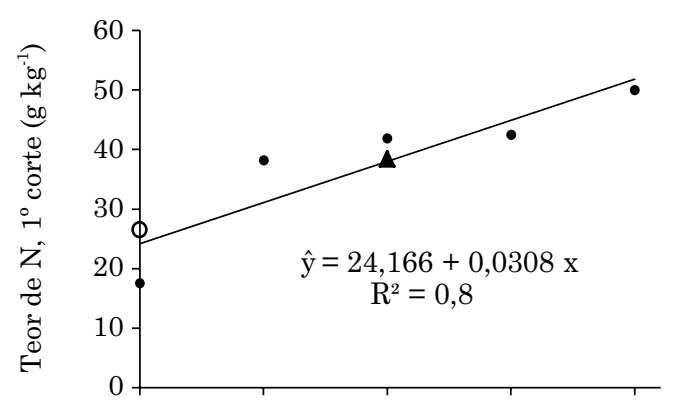

(c)

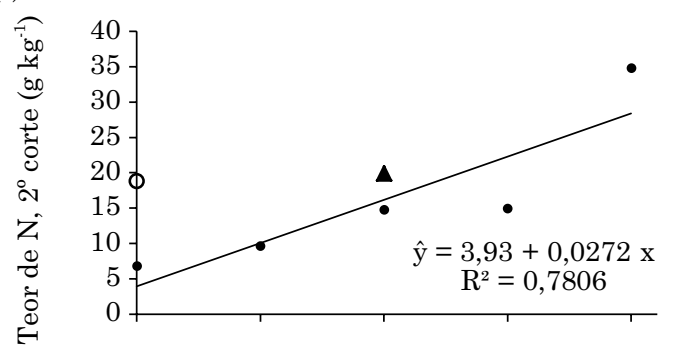

(e)

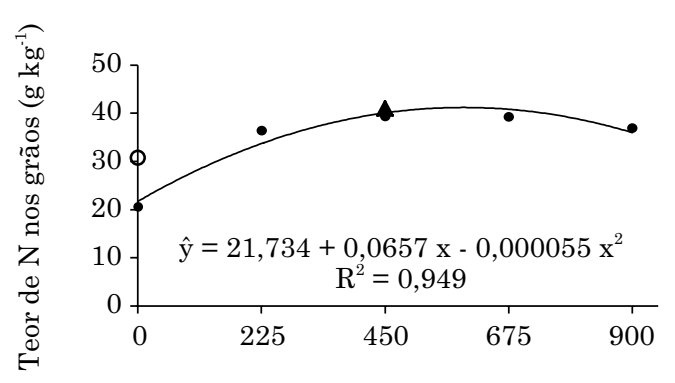

(b)

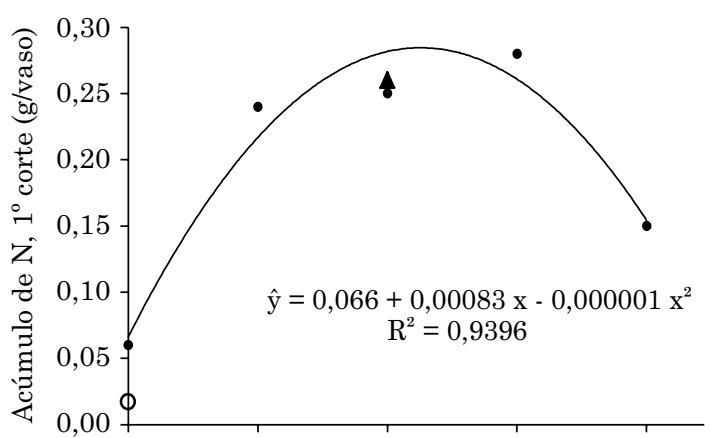

(d)

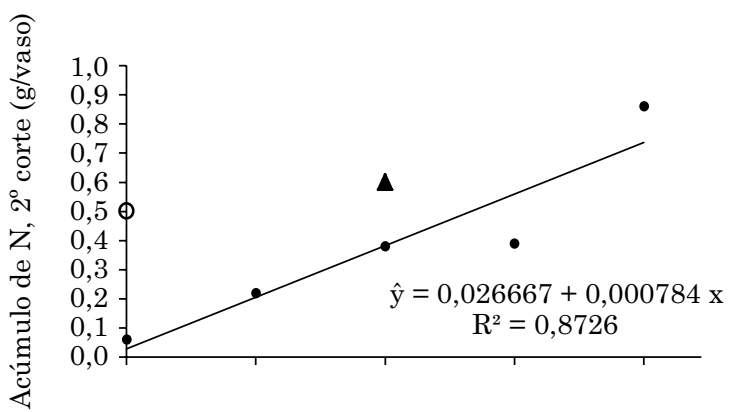

(f)

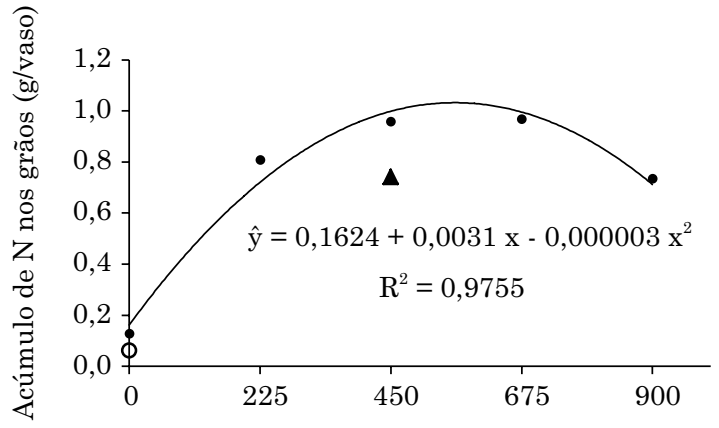

Dose de $\mathrm{N}\left(\mathrm{mg} \mathrm{kg}^{-1}\right)$

Figura 2. Teor e acúmulo de nitrogênio na parte aérea de plantas de trigo no $1^{\circ} \operatorname{corte}(\mathrm{a}, \mathrm{b})$ e no $2^{\circ} \operatorname{corte}$ $(c, d)$ e nos grãos (e, f) submetidas a doses de nitrogênio via colágeno de curtume e dois tratamentos adicionais, cultivadas em Latossolo Vermelho Distrófico típico.

acúmulos de $\mathrm{N}$ nas doses de 225,450 e $675 \mathrm{mg} \mathrm{kg}^{-1}$ de $\mathrm{N}$ fornecido via colágeno foram inferiores aos encontrados nas plantas que receberam $\mathrm{N}$ mineral. $\mathrm{Na}$ dose de $900 \mathrm{mg} \mathrm{kg}^{-1}$, não se encontrou diferença significativa. $\mathrm{O}$ acúmulo de $\mathrm{N}$ nos grãos nas doses 450 e $675 \mathrm{mg} \mathrm{kg}^{-1}$ do $\mathrm{N}$ via colágeno foi superior ao obtido com o fornecimento de $\mathrm{N}$ mineral. Nas doses de 225 e $900 \mathrm{mg} \mathrm{kg}^{-1}$, não houve diferenças de acúmulo em relação à fonte nitrogenada. É interessante observar que as plantas submetidas à adubação nitrogenada com colágeno apresentaram maior produção de grãos nas doses 450 e $675 \mathrm{mg} \mathrm{kg}^{-1}$.

\section{Acúmulo de Cr em plantas de trigo}

Os teores de $\mathrm{Cr}$ no trigo na parte aérea no $1^{\circ}$ corte e nos grãos apresentaram resposta quadrática ao incremento das doses de $\mathrm{N}$ via colágeno, com valores mínimos nas doses de 276 e $279 \mathrm{mg} \mathrm{kg}^{-1}$, respectivamente (Figura 3). Como os maiores incrementos de produção de matéria seca foram obtidos nas primeiras doses (Figura 1), as quantidades de Cr fornecidas pelo colágeno ficaram diluídas no tecido vegetal (Malavolta, 2006). Ao cultivar trigo com resíduo de rebaixadeira e aparas de couro curtido, Castilhos et al. (2002) encontraram teores $\mathrm{Cr}$ na parte aérea semelhantes às doses $0,225,450$ e $675 \mathrm{mg} \mathrm{kg}^{-1}$ de $\mathrm{N}$ fornecidos via colágeno (menor que $2,1 \mathrm{mg} \mathrm{kg}^{-1}$ no tecido foliar), sem reduzir o rendimento da cultura. No $2^{\circ}$ corte, o teor de $\mathrm{Cr}$ demonstrou resposta linear positiva com o aumento das doses de $\mathrm{N}$ fornecidas via colágeno. Os teores de $\mathrm{Cr}$ encontrados foram de 0,$94 ; 1,26 ; 3,12 ; 5,45$; e $7,61 \mathrm{mg} \mathrm{kg}^{-1}$ nas doses $0,225,450,675$ e $900 \mathrm{mg} \mathrm{kg}^{-1}$, respectivamente. 


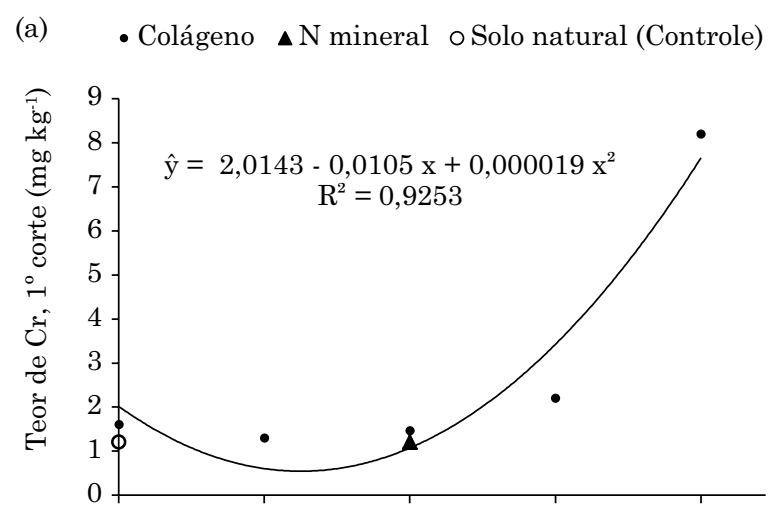

(b)

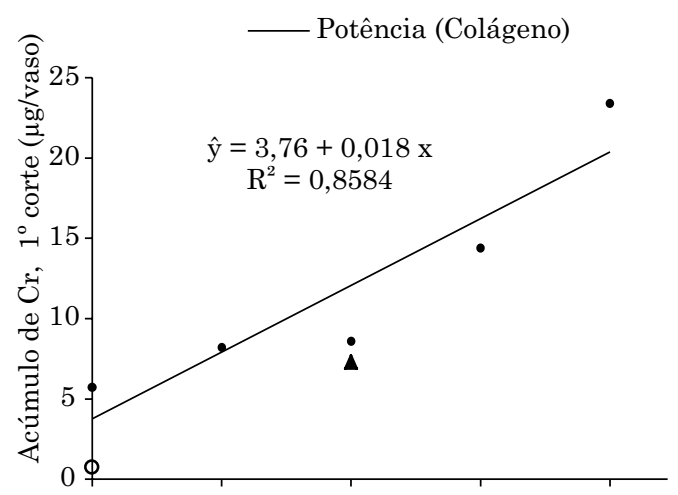

(d)

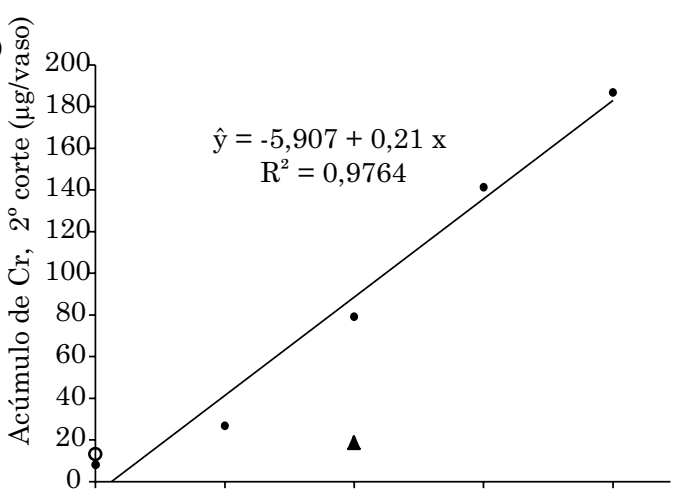

(f)

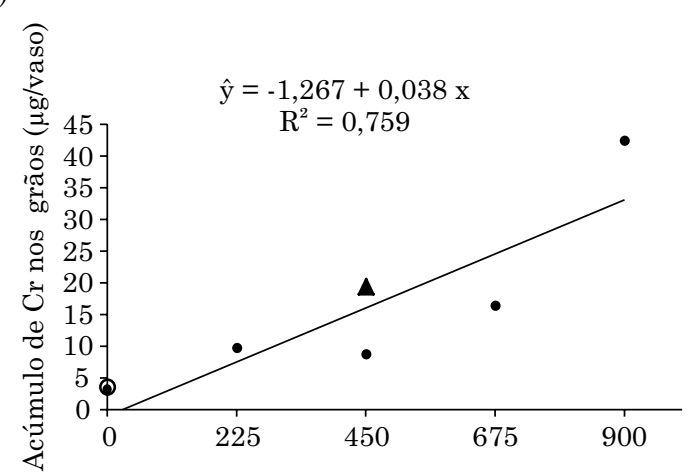

Dose de $\mathrm{N}\left(\mathrm{mg} \mathrm{kg}^{-1}\right)$

Figura 3. Teor e acúmulo de cromo na parte aérea de plantas de trigo no $1^{\circ}$ corte $(a, b)$ e no $2^{\circ}$ corte $(c, d)$ e nos grãos (e, f), submetidas a doses de nitrogênio via colágeno de curtume e dois tratamentos adicionais, cultivadas em Latossolo Vermelho Distrófico típico.

Os efeitos tóxicos de Cr para a maioria das plantas ocorrem em concentrações foliares superiores a 18,0 $\mathrm{mg} \mathrm{kg}^{-1}$ (Losi et al., 1994). Entretanto, Kabata-Pendias e Pendias (1984) citaram $2,0 \mathrm{mg} \mathrm{kg}^{-1}$ como valores de Cr toleráveis pelas culturas de interesse agronômico e $30,0 \mathrm{mg} \mathrm{kg}^{-1}$ de $\mathrm{Cr}$ como excessiva ou tóxica em folhas maduras, valores esses muito acima dos encontrados neste trabalho. Ressalta-se que apesar de os teores de $\mathrm{Cr}$ foliares encontrados serem superiores ao considerado tolerável para culturas agronômicas $\left(2 \mathrm{mg} \mathrm{kg}^{-1}\right)$, não se observou prejuízo para a produção de grãos.
Em grãos de trigo, Houba e Uittembogaard (1994) consideraram $0,42 \mathrm{mg} \mathrm{kg}^{-1}$ de $\mathrm{Cr}$ como teor normal. Teores de $\mathrm{Cr}$ superiores a esses foram encontrados nos grãos de trigo apenas quando da aplicação da maior dose de colágeno ( $\left.2,1 \mathrm{mg} \mathrm{kg}^{-1}\right)$, no tratamento-controle $\left(1,5 \mathrm{mg} \mathrm{kg}^{-1}\right)$ e na presença da ureia $\left(1,1 \mathrm{mg} \mathrm{kg}^{-1}\right) . \mathrm{O} \mathrm{Cr}$ é essencial para a dieta humana, sendo o $\mathrm{Cr}^{3+}$ a forma nutricional utilizada, cuja ingestão recomendada para adultos varia entre 0,05 e 0,2 $\mathrm{mg} \mathrm{d}^{-1}$ (Moreira e Teixeira, 2003). Os resultados dessa pesquisa instigam estudos voltados à adição de $\mathrm{Cr}$ aos tecidos vegetais com fins nutricionais, sem que haja comprometimento de produção agrícola e ambiental. 
Os acúmulos de Cr na parte aérea das plantas de trigo no $1^{\circ}$ e $2^{\circ}$ cortes, assim como nos grãos, aumentaram linearmente com as doses de $\mathrm{N}$ fornecidas via colágeno (Figura 3); e, de maneira geral, esse fornecimento gerou teores e acúmulos de $\mathrm{Cr}$ superiores àqueles encontrados nas plantas, onde o $\mathrm{N}$ foi fornecido via ureia. Apesar da extração de grande parte do $\mathrm{Cr}$ contido nos resíduos de wet blue após tratamento, o colágeno utilizado permaneceu com $1.986 \mathrm{mg} \mathrm{kg}^{-1}$ de Cr remanescente, que é potencialmente disponível para as plantas.

\section{Produção de matéria seca em plantas de arroz}

As plantas de arroz responderam ao aumento das doses de N, sendo quadrática a resposta da produção de matéria seca dos grãos e de parte aérea no $1^{\circ}$ corte e linear para produção de matéria seca no $2^{\circ}$ corte e de cascas dos grãos (Figura 4). O colágeno como fonte residual de $\mathrm{N}$ proporcionou, nas doses $675 \mathrm{e}$ $900 \mathrm{mg} \mathrm{kg}^{-1}$, produção de matéria seca das plantas de arroz igual ou superior, quando comparado aos tratamentos com $\mathrm{N}$ mineral com ou sem reposição. A aplicação adicional de ureia para o arroz foi positiva para a produção de grãos e matéria seca da parte aérea no $2^{\circ}$ corte. Todavia, a ausência de diferença significativa no $1^{\circ}$ corte indicou que a quantidade de $\mathrm{N}$ adicionada (450 $\mathrm{mg} \mathrm{kg}^{-1}$ de $\mathrm{N}$ mineral) no cultivo do trigo proporcionou uma quantidade de $\mathrm{N}$ residual, passível de utilização no início do cultivo de arroz. Ao fornecer apenas $225 \mathrm{mg} \mathrm{kg}^{-1}$ de $\mathrm{N}$ via colágeno, no primeiro cultivo com trigo, a cultura do arroz apresentou produções de matéria seca inferiores àquelas encontradas quando utilizaram-se $450 \mathrm{mg} \mathrm{kg}^{-1}$ de $\mathrm{N}$ mineral.

Em relação à adubação com $\mathrm{N}$ mineral, a produção de grãos de trigo foi superior em todos os tratamentos onde o $\mathrm{N}$ foi proveniente do colágeno, com destaque para as doses 450 e $675 \mathrm{mg} \mathrm{kg}^{-1}$ (Quadro 1). No tratamento-controle (solo natural) e na dose $0 \mathrm{mg} \mathrm{kg}^{-1} \mathrm{de} \mathrm{N}$ via colágeno, observou-se redução de 88 e $64 \%$ na produção de grãos, respectivamente. Para o arroz, notou-se que a produção relativa de grãos na dose $675 \mathrm{mg} \mathrm{kg}^{-1} \mathrm{de}$ $\mathrm{N}$ proveniente do colágeno foi semelhante àquela encontrada quando o $\mathrm{N}$ foi reposto de forma mineral.

Enquanto o $\mathrm{N}$ mineral é todo disponibilizado na $1^{a}$ aplicação, a disponibilização do $\mathrm{N}$ do colágeno ocorre mais lentamente via degradação microbiana da matéria orgânica, evitando perdas e fornecendo rendimento de grãos semelhante àquele encontrado no tratamento cujo $\mathrm{N}$ é reposto na forma de ureia.

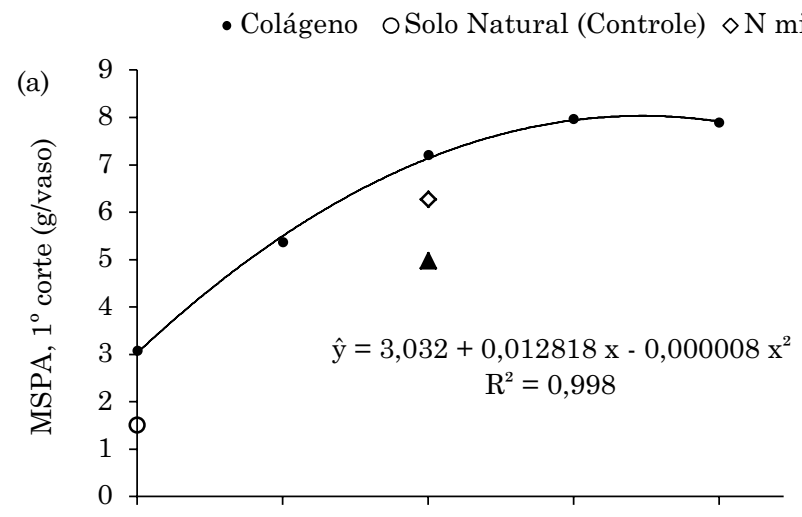

(b)

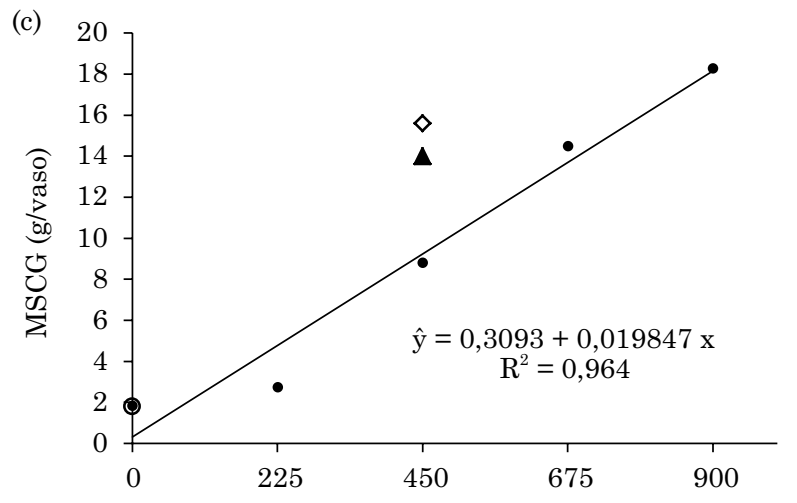

(d)
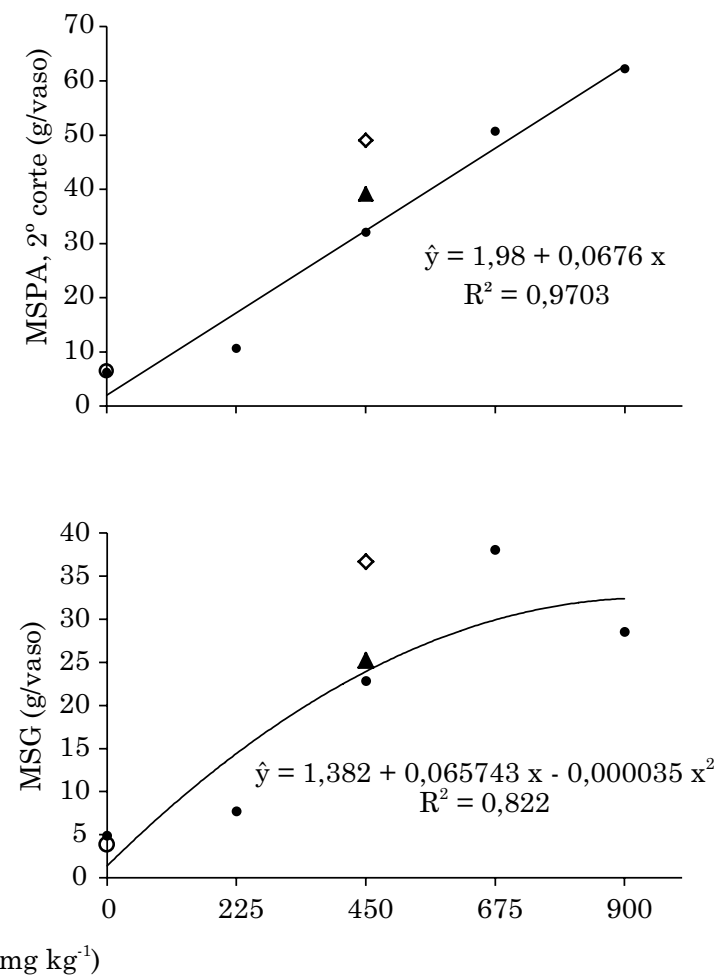

Figura 4. Produção de matéria seca da parte aérea (MSPA) no $1^{\circ}$ corte (a), no $2^{\circ}$ corte (b), nas cascas dos grãos (MSCG) (c) e nos grãos (MSG) (d) em plantas de arroz submetidas a doses de nitrogênio via colágeno de curtume e três tratamentos adicionais, cultivadas em Latossolo Vermelho Distrófico típico. 
Quadro 1. Produção relativa de grãos de trigo e arroz em sucessão nas diferentes doses de nitrogênio aplicadas via colágeno e no tratamento-controle, em relação à adubação com ureia, cultivados em Latossolo Vermelho Distrófico típico

\begin{tabular}{|c|c|c|c|c|c|c|c|}
\hline \multirow{2}{*}{\multicolumn{2}{|c|}{$\mathrm{N}$ mineral (Ureia) }} & \multirow{2}{*}{ Controle } & \multicolumn{5}{|c|}{ Dose de $\mathrm{N}$ via colágeno $\left(\mathrm{mg} \mathrm{kg}^{-1}\right)$} \\
\hline & & & \multirow[t]{2}{*}{$\mathbf{0}$} & \multirow[t]{2}{*}{225} & \multirow[t]{2}{*}{450} & \multirow[t]{2}{*}{675} & \multirow[t]{2}{*}{900} \\
\hline \multicolumn{3}{|c|}{$\%$} & & & & & \\
\hline \multicolumn{8}{|c|}{ Trigo } \\
\hline \multicolumn{2}{|c|}{100} & 12 & 36 & 126 & 139 & 141 & 114 \\
\hline \multicolumn{8}{|c|}{ Arroz } \\
\hline $\mathrm{C} /$ reposição & $\mathrm{S} /$ reposição & & & & & & \\
\hline 100 & 69 & 11 & 14 & 22 & 64 & 106 & 80 \\
\hline
\end{tabular}

- Colágeno o Solo Natural (Controle) $\diamond \mathrm{N}$ mineral com reposição $\Delta \mathrm{N}$ mineral sem reposição

(a)

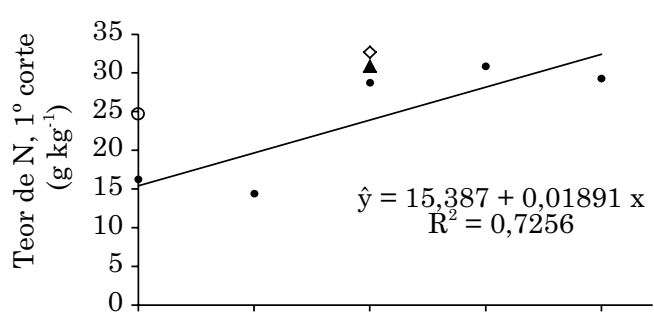

(c)

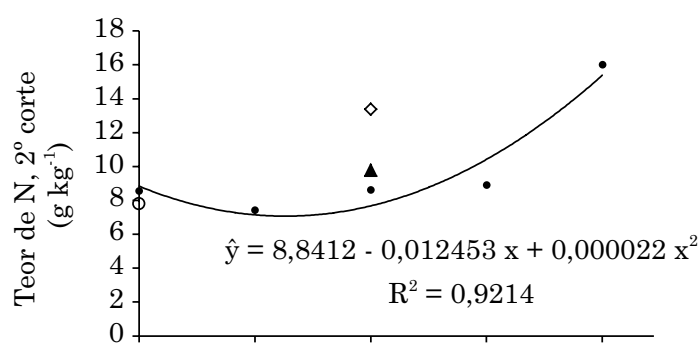

(e)

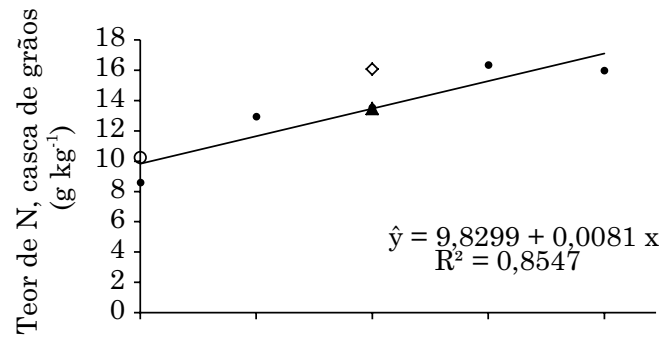

(g)

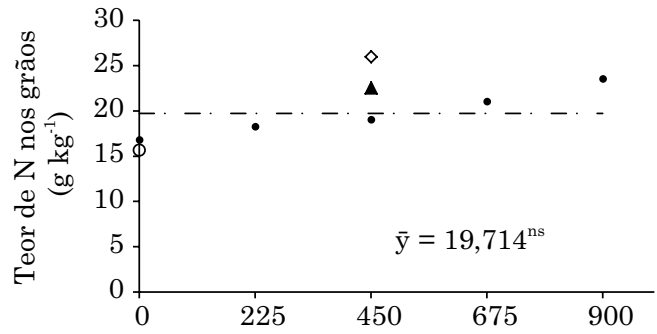

(b)

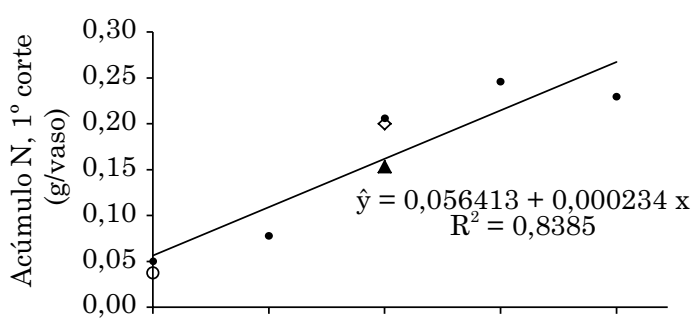

(d)

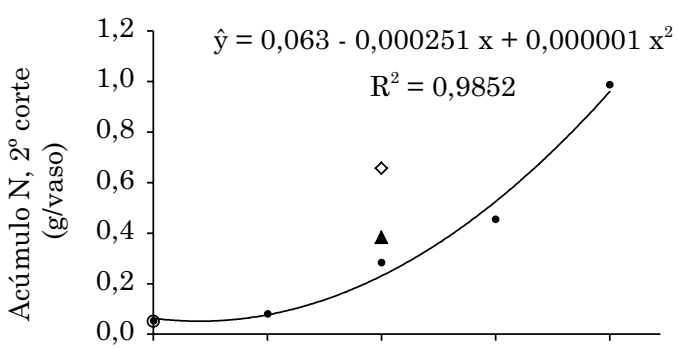

(f)

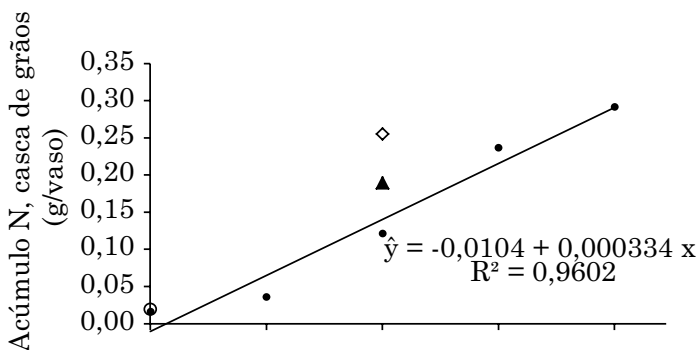

(h)

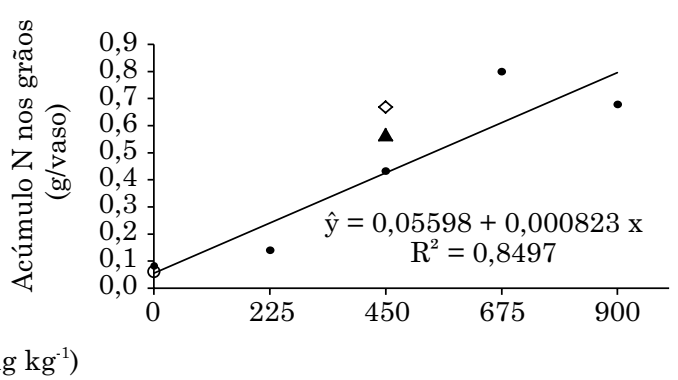

Figura 5. Teor e acúmulo de nitrogênio na parte aérea no $1^{\circ}$ corte $(a, b)$, no $2^{\circ}$ corte (c, d), nas cascas de grãos (e, f) e nos grãos $(g, h)$ em plantas de arroz submetidas a doses de nitrogênio via colágeno de curtume e três tratamentos adicionais, cultivadas em Latossolo Vermelho Distrófico típico. ns: não significativo. 
Com isso, as respostas obtidas com o colágeno proporcionariam duas vantagens: diminuição da dose de $\mathrm{N}$ mineral e da mão-de-obra com as aplicações. Em plantas de feijão cultivadas em solo tratado com colágeno em um cultivo anterior com capim-elefante, Lima et al. (2010) constataram crescimento semelhante das plantas com a adubação convencional e das plantas supridas com o colágeno na dose de $16 \mathrm{Mg} \mathrm{ha}^{-1}$. Esses resultados associados aos encontrados para a massa de matéria seca da parte aérea demonstraram o potencial de utilização do colágeno na agricultura.

\section{Acúmulo de $\mathrm{N}$ em plantas de arroz}

Os teores e acúmulos de $\mathrm{N}$ na parte aérea das plantas de arroz no $1^{\circ}$ corte aumentaram linearmente com a elevação das doses de $\mathrm{N}$ fornecidas via colágeno (Figura 5). Nas doses superiores a $225 \mathrm{mg} \mathrm{kg}^{-1}$ de $\mathrm{N}$ via colágeno, os teores foliares não diferiram dos teores (a)

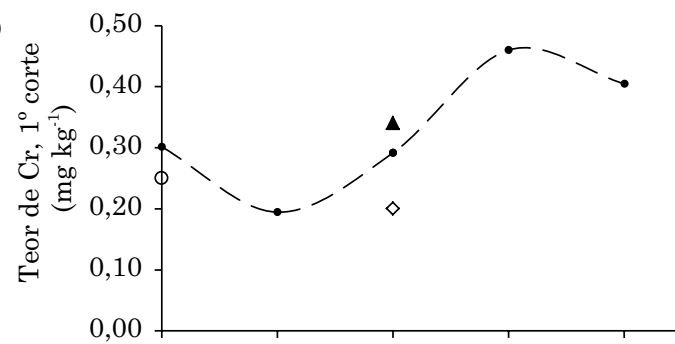

(c)

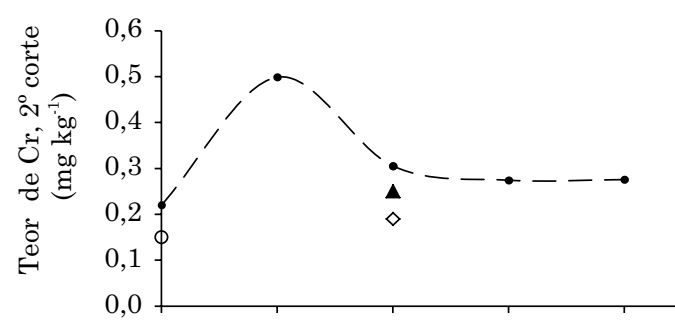

(e)

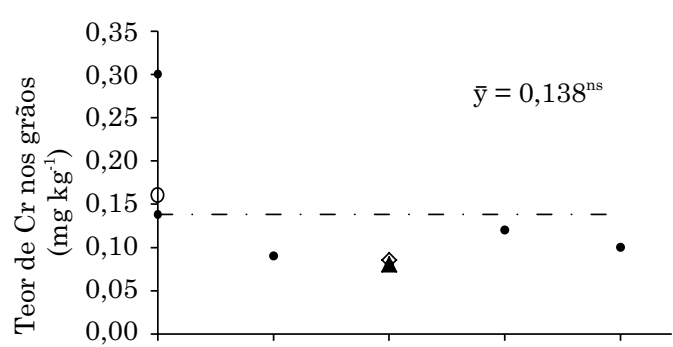

(g)

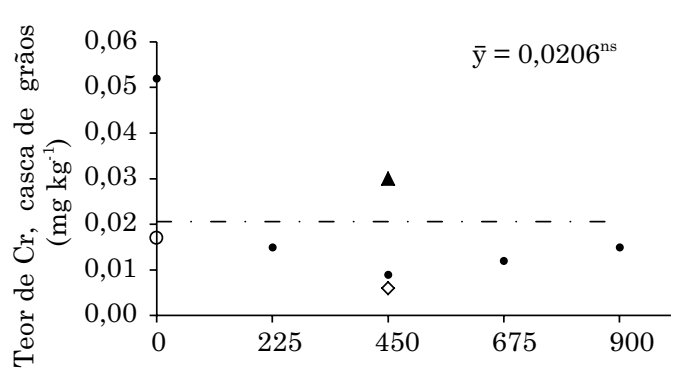

(b)

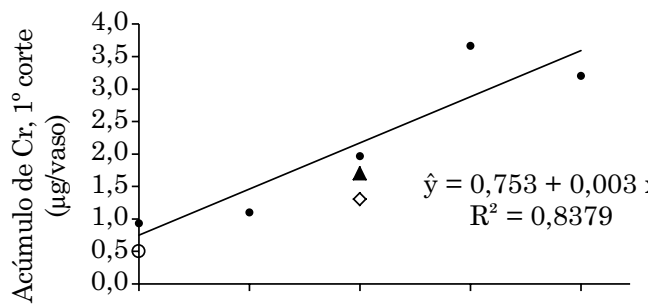

(d)

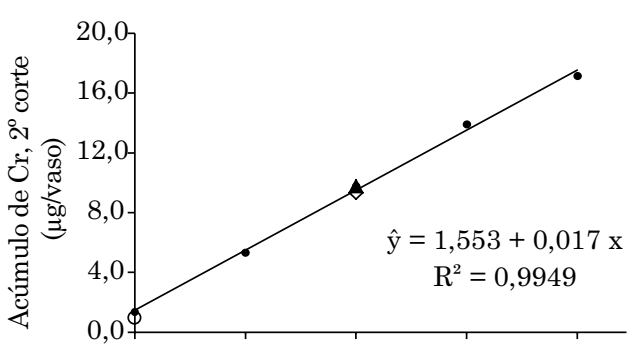

(f)

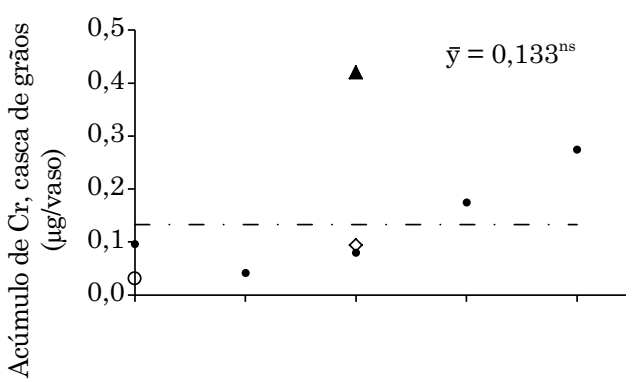

(h)

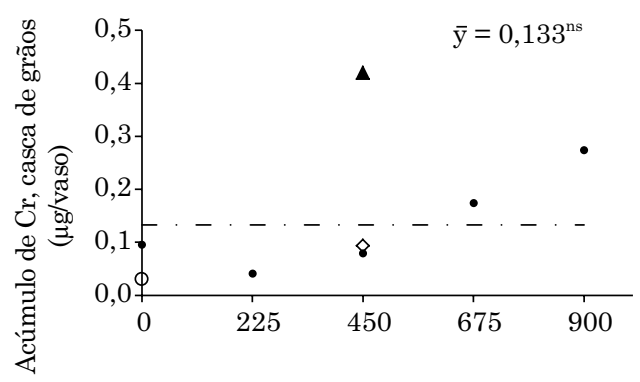

Dose de N (mg kg $\left.{ }^{-1}\right)$

Figura 6. Teor e acúmulo de cromo na parte aérea no $1^{\circ}$ corte $(a, b)$, no $2^{\circ}$ corte (c, d), nas cascas de grãos $(e, f)$ e nos grãos $(g, h)$ em plantas de arroz submetidas a doses de nitrogênio via colágeno de curtume e três tratamentos adicionais, cultivadas em Latossolo Vermelho Distrófico típico. ns: não significativo. 
encontrados nas plantas tratadas com $\mathrm{N}$ mineral, com ou sem reposição. A ausência de diferença significativa de teor, com e sem reposição de ureia no $1^{\circ}$ corte, sustenta a hipótese do $\mathrm{N}$ residual, passível de utilização no início do $2^{\circ}$ cultivo. No $1^{\circ}$ corte, os teores de $\mathrm{N}$ na parte aérea das plantas em que o $\mathrm{N}$ foi fornecido via colágeno nas doses 450,675 e $900 \mathrm{mg} \mathrm{kg}^{-1}\left(28,7\right.$; 30,8; e $39,3 \mathrm{~g} \mathrm{~kg}^{-1}$, respectivamente) se encontram dentro da faixa de teores foliares descrita como adequada por Fageria et al. (1995) para a cultura do arroz, nessa fase do crescimento (período imediatamente anterior à floração). No $2^{\circ}$ corte, os teores e acúmulos de $\mathrm{N}$ nas plantas que receberam $\mathrm{N}$ via colágeno evidenciaram resposta quadrática, com valor mínimo na dose $283 \mathrm{mg} \mathrm{kg}^{-1}$ para teor e $126 \mathrm{mg} \mathrm{kg}^{-1}$ para acúmulo. Tanto para teor quanto para acúmulo de $\mathrm{N}$, diferenças significativas entre $\mathrm{N}$ fornecido via ureia e $\mathrm{N}$ fornecido via colágeno foram encontradas apenas na dose de $\mathrm{N}$ via colágeno equivalente a $900 \mathrm{mg} \mathrm{kg}^{-1}$.

Os teores de $\mathrm{N}$ nos grãos não responderam às doses de $\mathrm{N}$ fornecido via colágeno, com média de $19,71 \mathrm{mg} \mathrm{kg}^{-1}$. O acúmulo de $\mathrm{N}$ nos grãos evidenciou resposta linear às doses de $\mathrm{N}$ aplicadas via colágeno, sendo superior à aplicação via ureia apenas na dose de $675 \mathrm{mg} \mathrm{kg}^{-1}$. Nesse caso, o maior acúmulo se deu em razão da produção de grãos, já que o teor não apresentou diferença entre os tratamentos.

\section{Acúmulo de Cr em plantas de arroz}

Os teores de $\mathrm{Cr}$ encontrados não atingiram a faixa considerada como excessiva ou tóxica em folhas maduras, que é de $18 \mathrm{mg} \mathrm{kg}^{-1}$ (Kabata-Pendias e Pendias, 2001), em nenhuma das doses de $\mathrm{N}$ estudadas (Figura 6). O Cr residual no solo é pouco tóxico para as plantas, sendo facilmente imobilizado e pouco absorvido (Shanker et al., 2005). Por isso, respostas não significativas (Figuras 6e, $6 \mathrm{~g}$ e $6 \mathrm{~h}$ ) ou não ajustadas (Figura 6f) foram observadas para os teores encontrados nos grãos e nas cascas dos grãos. Os teores de $\mathrm{Cr}$ encontrados neste trabalho foram semelhantes ou inferiores aos encontrados por Castilhos et al. (2002), em plantas de trigo tratadas com resíduo de rebaixadeira e aparas de couro. Já os teores de $\mathrm{Cr}$ detectados no tratamento onde o $\mathrm{N}$ foi fornecido via ureia foram semelhantes aos encontrados nas plantas onde o $\mathrm{N}$ via colágeno foi aplicado.

\section{Teor de Cr no solo}

Foram observados maiores teores de $\mathrm{Cr}$ no solo nos tratamentos que receberam colágeno, e esse teor foi maior, quanto maior a dose de colágeno aplicada (Quadro 2). A mesma situação se repetiu no pós-plantio do trigo. Todavia, após o plantio do arroz, os valores não evidenciaram diferenças estatísticas entre os tratamentos, tendendo a uma estabilização desses teores no solo.
Quadro 2. Teores de cromo no solo em cultivos seguidos de trigo e arroz, quando fertilizados com doses de nitrogênio via colágeno de curtume e via ureia

\begin{tabular}{|c|c|c|c|}
\hline \multirow[b]{2}{*}{ Tratamento } & \multicolumn{3}{|c|}{ Teor de $\mathrm{Cr}$} \\
\hline & $\begin{array}{l}\text { Pré-plantio } \\
\text { trigo }\end{array}$ & $\begin{array}{l}\text { Pós-plantio } \\
\text { trigo }\end{array}$ & $\begin{array}{l}\text { Pós-plantio } \\
\text { arroz }\end{array}$ \\
\hline & \multicolumn{3}{|c|}{$\mathrm{mg} \mathrm{kg}^{-1}$} \\
\hline $\begin{array}{l}0 \mathrm{mg} \mathrm{kg}^{-1} \mathrm{~N} \text { via } \\
\text { colágeno }\end{array}$ & $316 \mathrm{~b}$ & $289 \mathrm{a}$ & $311 \mathrm{a}$ \\
\hline $\begin{array}{l}225 \mathrm{mg} \mathrm{kg}^{-1} \mathrm{~N} \text { via } \\
\text { colágeno }\end{array}$ & $264 \mathrm{~b}$ & $290 \mathrm{a}$ & $289 \mathrm{a}$ \\
\hline $\begin{array}{l}450 \mathrm{mg} \mathrm{kg}^{-1} \mathrm{~N} \text { via } \\
\text { colágeno }\end{array}$ & $292 \mathrm{~b}$ & $292 \mathrm{a}$ & $279 \mathrm{a}$ \\
\hline $\begin{array}{l}675 \mathrm{mg} \mathrm{kg}^{-1} \mathrm{~N} \text { via } \\
\text { colágeno }\end{array}$ & $306 \mathrm{a}$ & $293 \mathrm{a}$ & $272 \mathrm{a}$ \\
\hline $\begin{array}{l}900 \mathrm{mg} \mathrm{kg}^{-1} \mathrm{~N} \text { via } \\
\text { colágeno }\end{array}$ & $313 \mathrm{a}$ & $277 \mathrm{a}$ & $312 \mathrm{a}$ \\
\hline $\begin{array}{l}450 \mathrm{mg} \mathrm{kg}^{-1} \mathrm{~N} \text { via } \\
\text { ureia com reposição }\end{array}$ & $295 \mathrm{~b}$ & $308 \mathrm{a}$ & $297 \mathrm{a}$ \\
\hline $\begin{array}{l}450 \mathrm{mg} \mathrm{kg}^{-1} \mathrm{~N} \text { via } \\
\text { ureia sem reposição }\end{array}$ & $271 \mathrm{~b}$ & $285 \mathrm{a}$ & $306 \mathrm{a}$ \\
\hline Solo natural & $261 \mathrm{~b}$ & $257 \mathrm{a}$ & $292 \mathrm{a}$ \\
\hline
\end{tabular}

Valores seguidos da mesma letra na coluna não diferem entre si pelo teste de Scott-Knott a $5 \%$.

\section{CONCLUSÕES}

A aplicação de até $675 \mathrm{mg} \mathrm{kg}^{-1}$ de nitrogênio via colágeno de curtume propiciou produção de matéria seca de plantas de trigo similar à aplicação de $\mathrm{N}$ mineral

A produção de grãos de trigo com o uso de colágeno foi superior em todas as doses estudadas em relação ao tratamento com $\mathrm{N}$ mineral.

O acúmulo de cromo nas plantas de trigo aumentou linearmente com a aplicação do colágeno.

Como fonte residual, a aplicação do colágeno de curtume proporcionou níveis de $\mathrm{N}$ no solo suficientes para boa obtenção de massa de grãos de arroz em sucessão ao cultivo de trigo.

\section{REFERÊNCIAS}

Abichequer AD, Lisboa BB, Radin B, Dorneles EP, Vargas LK, Alflen MP, Lorscheiter R, Esteres LFR, Iranço FA, Zanotelli VH. Rendimento de grãos, crescimento e teor de $\mathrm{N}$ na folha de milho fertilizado com adubo orgânico de resíduos de couro. In: Anais da Reunião Sulbrasileira de Ciência do Solo [CD-ROM]; 2008; Santa Maria. Santa Maria: SBCS; 2008.

Associação Brasileira de Normas Técnicas - ABNT. NBR 10004: classificação de resíduos sólidos. Rio de Janeiro: 2004.

Bataglia OC, Furlani AMC, Teixeira JPF, Furlam PR, Gallo JR. Métodos de análise química de plantas. Campinas: Instituto Agronômico de Campinas; 1983. (Boletim técnico,78). 
Becquer T, Quantin C, Sicot M, Boudot JP. Chromium availability in ultramafic soils from New Caledonia. Sci Total Environ. 2003;301:251-61.

Brasil. Ministério da Agricultura Pecuária e Abastecimento. Manual de métodos analíticos oficiais para fertilizantes minerais, orgânicos, organominerais e corretivos. Brasília, DF: 2007.

Cary EE, Allaway WH, Olson OE. Control of chromium concentrations in food plants. Chemistry of chromium in soils and its availability to plants. J Agric Food Chem. 1977;25:305-9.

Castilhos DD, Tedesco MJ, Vidor C. Rendimentos de culturas e alterações químicas do solo tratado com resíduos de curtume e crômio hexavalente. R Bras Ci Solo. 2002;26:1083-92.

Empresa Brasileira de Pesquisa Agropecuária - Embrapa. Centro Nacional de Pesquisa de Solos. Manual de métodos de análise de solo. $2^{\text {a }}$.ed. Rio de Janeiro: 1997.

Empresa Brasileira de Pesquisa Agropecuária - Embrapa. Sistema brasileiro de classificação de solo. Brasília, DF: Serviço de Produção de Informação; 2006.

Erdem M, Ozverdi A. Leaching behavior of chromium in chrome shaving generated in tanning process and its stabilization. J Hazard Mater. 2008;156:51-5.

Fageria NK, Ferreira E, Prabhu AS, Barbosa Filho MP, Filippi MC. Seja o doutor do seu arroz. Piracicaba: Potafos; 1995. (Arquivo do Agrônomo, 9).

Ferreira DF. SISVAR software: versão 4.6. [Software]. Lavras: UFLA/DEX; 2003.

Houba VJG, Uittenbogaard J. Chemical composition of various plant species. Wageningen: Wageningen Agricultural University; 1994.

Huffer S, Taeger T. Sustainable leather manufacturing a topic with growing importance. J Am Leather Chem Assoc. 2004;99:423-8.

James BR, Bartlett RJ. Behavior of chromium in soils. Interactions between oxidation-reduction and organic complexation. J Environ Qual. 1983;12:173-6.

Kabata-Pendias A, Pendias H. Trace elements in soils and plants. $2^{\text {nd }}$.ed. Boca Raton: CRC; 1984.

Kolomaznik K, Adamek M, Andel I, Uhlirova M. Leather waste: potential threat to human health, and a new technology of its treatment. J Hazard Mater. 2008;160:514-20.

Lima DQ, Oliveira LCA, Bastos ARR, Carvalho GS, Marques JGSM, Carvalho JG, Souza GA. Leather industry solid waste as nitrogen source for growth of common bean plants. Appl Environ Soil Sci. 2010;ID703842:1-7.

Losi ME, Amrhein C, Frankenberger Júnior WT. Environmental biochemistry of chromium. Rev Environ Contam Toxicol. 1994;136:91-121.
Malavolta E, Vitti GC, Oliveira SA. Avaliação do estado nutricional das plantas: princípios e aplicações. $2^{\mathrm{a}}$.ed. Piracicaba: Potafos; 1997.

Malavolta E. Elementos de nutrição mineral de plantas. São Paulo: Agronômica Ceres; 1980.

Malavolta E. Manual de nutrição mineral de plantas. São Paulo: Agronômica Ceres; 2006.

Mertz W. Chromium occurrence and function in biological systems. Physiol Rev. 1969;49:163-239.

Moreira MV, Teixeira RC. Estado da arte tecnológico em processamento do couro: revisão bibliográfica no âmbito internacional. Porto Alegre: Centro Nacional de Tecnologias Limpas; 2003.

Nogueira FGE, Castro IA, Bastos ARR, Souza GA, Carvalho JG, Oliveira LCA. Recycling of solid waste rich in organic nitrogen from leather industry: mineral nutrition of rice plants. J Hazard Mater. 2010;186:1064-9.

Oliveira DQL, Carvalho KTG, Bastos ARR, Oliveira LCA, Marques JJGSM, Nascimento RSMP. Utilização de resíduos da indústria de couro como fonte nitrogenada para o capim-elefante. R Bras Ci Solo. 2008;32:417-24.

Oliveira LCA, Dallago RM, Nascimento Filho I. Processo de reciclagem dos resíduos sólidos de curtumes por extração do cromo e recuperação do couro descontaminado. Brasil patente BR 001538. 2004.

Rai D, Eary L, Zachara E. Environmental chemistry of chromium. Sci Total Environ. 1989;86:15-23.

Ribeiro AC, Guimaraes PTG, Alvarez V VH, editores. Recomendação para o uso de corretivos e fertilizantes em Minas Gerais: $5^{\mathrm{a}}$. Aproximação. Viçosa, MG: Comissão de Fertilidade do Solo do Estado de Minas Gerais; 1999.

Ribeiro EMP. Produção e análise físico-química do adubo de descarte de couro bovino com ênfase no impacto ambiental e energético[tese]. Porto Alegre: Universidade Federal do Rio Grande do Sul; 2006.

Shanker AK, Cervantes C, Loza-Tavera LL, Avudainayagam S. Chromium toxicity in plants. Environ Int. 2005;31:739-53.

Silva S. Agricultural use of leather working residues as means of energy saving and environmental protection. Milão: UNIC; 1989.

Taiz L, Zeiger E. Fisiologia vegetal. $3^{\text {a }}$.ed. Porto Alegre: Artmed; 2004.

United States Enviromental Protection Agency - USEPA. Method 3051 A: micro-wave assisted acid digestion of sediments sludges, soils and oils. In: Sw-846: test methods for evaluation solid waste physical and chemical methods. Washington, DC: 1998. p.1-20. 